\title{
Finding a Way: More Tales of Dyslexia and Dyspraxia in Psychophysical Actor Training.
}

\section{Daron Oram}

Royal Central School of Speech and Drama, University of London, UK

daron.oram@cssd.ac.uk

Daron Oram is a Senior Lecturer in Voice, working with students on both the BA Acting:

Collaborative and Devised Theatre and the MA/MFA in Voice Studies: Teaching and Coaching programs at the Royal Central School of Speech and Drama. Daron's practice-based research focuses on diversity, inclusion and equality within actor training as well as the intersection of psychophysical approaches to acting and voice. Daron is an alumnus of the Central voice course, a Designated Linklater Teacher, and a Senior Fellow of the Higher Education Academy. 


\section{Finding a Way: More Tales of Dyslexia and Dyspraxia in Psychophysical Actor Training.}

This article proposes a radical paradigm shift for actor training and voice training.

Using heuristic practice-based research findings, the article highlights how progressive education methods at the heart of psychophysical actor training dysconsciously discriminate against students who are dyslexic and/or dyspraxic learners. It discusses the psychological and cognitive impact of experiential learning models on neurodiverse acting students and challenges the widely held "truths" in this training. The article draws on the philosophical framework proposed by Jacques Rancière in his discussion of the emancipatory pedagogy of Joseph Jacotot, The Ignorant Schoolmaster, to offer an alternative perspective on actor training that starts from an assumption of equality, rather than a position where equality is a distant objective. The author argues that it is possible to reject a hierarchical expert-novice approach to training and implement a process of collaboration with students as fellow artists. The article reviews the position of knowledge within psychophysical training, and the author rejects the use of a universal language of experiences. The author proposes that, by trusting the student's ability to learn what is needed, actor trainers can adopt a position of ignorance in relation to a student's own self-knowledge. Finally, the author incorporates this work into a revised vocal pedagogy that embraces neurodiversity and effectively engages all students' will to learn with full attention.

Keywords: Acting, Voice, Pedagogy, Dyslexia, Dyspraxia, Critical Pedagogy, Rancière

\section{Introduction}

In this article, I discuss an approach to training actors' voices based on the work of Kristin Linklater's Freeing the Natural Voice (Linklater 2006), which uses an experiential approach to training that is common to many leading voice practitioners' work stemming from the twentieth century, such as Cicely Berry, Patsy Rodenberg and Catherine Fitzmaurice. In her introduction to Freeing the Natural Voice, Linklater discusses child development and notes how a process of socialization leads to the development of habits that hinder vocal expression. The training method she proposes takes students through a progression of voice exercises to remove unnecessary tensions and "free, develop and strengthen the voice" (2006, 7). 
My research identifies how dyslexic and/or dyspraxic learners demonstrate strengths related to acting and theatre making; however, experiential learning and progressive education used in psychophysical actor training dysconsciously discriminates against them. Educational theorists, Charles Bingham and Gert Biesta, state that "education is commonly described in one of three ways. These ways roughly correspond to the traditional, progressive and critical models of education" $(2010,110)$. Traditional education is "conceived as a platform for disseminating a common set of learnings" (111). In other words, the teacher passes on their knowledge to the student via direct instruction. The progressive model draws on the psychological development of the child and asks that teaching "be grounded in the particular experience of each person" (111). This approach can be seen in Linklater's discussion of socialization and vocal habits. In this article, I show how I have built on my earlier research findings to move towards a critical approach to voice pedagogy. In the critical approach "education itself is identified as a tool that has been used by the state to foster inequality" (110), inequality which the critical approach then seeks to address. In this article, I show how inequality is experienced by neurodiverse students and how they might be liberated from this by a change in approach. I use the term neurodiverse to refer to students who are dyslexic and/or dyspraxic learners even though this term typically includes a wider range of learning differences.

The first phase of my research used a mixed methodological approach in a heuristic, grounded theory case study. American psychologist, Clark Moustakas' heuristic process,

Can be envisaged as a process of personal immersion in a topic or question, leading to new insights $[\ldots]$ this process can be characterised by a willingness to surrender to the research question, to a sufficient extent that a personal transformation can take place. (J. McLeod 2011, 206-7)

Moustakas describes the seven stages of heuristic process as initial engagement, immersion, incubation, illumination, explication, and creative synthesis (Moustakas 1990). In my previous article (Oram 2018), I discussed my own process of "surrender" to the research and how I had reached a point of "transformation/illumination" using focus groups, reflective practice and peer observations ${ }^{1}$. As a result, I was able to identify a set of emergent theories relating to the neurodiverse student experience. I briefly review these emergent theories in the following section before moving on to discuss the methodological approach to this second phase of research, in which I have moved through the final heuristic stages of explication, and creative synthesis.

\section{Unknown Currents: Progressive Education and the Dyslexic and/or Dyspraxic Learner}

The emergent findings of my first phase of research indicated that experiential learning methods used in psychophysical actor training disadvantage neurodiverse students in two overlapping ways, one cognitive and one psychological. The cognitive findings show that many training methods cause students to struggle to attend to their own psychophysical experiences. To understand these findings, I drew on the neuroscientific research of Norman Farb et al. (2007). Their research identifies two modes of self-reference and their corresponding neural patterns: the "Experiencing Function" (EF) and the "Narrative Function" (NF). These functions are shown to be inversely proportionate, which means that the more a person tunes into their sensory experience (EF) the less they will be able to register their narrative thoughts (NF) and vice versa. Typically, a student who finds 
themselves working in the narrative mode will describe it as a sense of being "stuck in their head" rather than being able to tune into the sensations in their body.

I have shown that there are a range of activities common to psychophysical training (Oram 2018, 59-60), which cause neurodiverse students' attention to shift from an experiential (EF) mode and into a narrative (NF) mode. The range of these activities is extensive and includes: following a long progression of guided exploration, working eyesclosed, and translating visual imagery or verbal instructions into physical experience. Once neurodiverse students shift into a narrative (NF) mode, they will continue to work hard and do the prescribed work. However, in this narrative mode, they cannot sense what is going on in their body (EF). In these cases, if they do feedback to the group, they might well say that they "felt nothing":

Often, it's a long routine and at the end you'll feedback but [...] you really don't know what you were meant to do or feel or say or think [...] consciously $[\mathrm{NF}]$, you know why you are doing it but there is something missing [EF]. (Focus Group)

Alongside this cognitive issue, I have shown a corresponding psychological impact of experiential learning approaches. This psychological impact causes neurodiverse students to experience a "cycle of failure" (Oram 2018, 63) that has a direct impact upon their selfesteem and engagement. The student above, who says that they "felt nothing" in the experiential work, will compare their experiences to the feedback spoken by neurotypical ${ }^{2}$ classmates, who may be experiencing an exciting new sense of their voice in their body and are eager to share that with the group. Dyslexic and/or dyspraxic learners describe how, at times like these, they tend to think, "I didn't feel that; I must be doing it wrong" (Focus Group). Neurodiverse students are more likely to assume they are doing something wrong as they will likely have experienced regular feelings of failure at key points in their education, either in the classroom or on the sports field:

I knew it was going to be hard [...] things like movement and bio-mechanics sent me back to when I was five or six and felt I was always the odd one out [...] I thought I would feel that other people would get my brain, but they still don't! (Focus Group)

Experiences like these are part of the cycle of failure. This cycle is continued and exacerbated by the exploratory exercises at the heart of the progressive education model. During these exercises students are often asked to "see what happens" or told that "there is no right or wrong". When given these instructions, neurodiverse students tend to assume that they are doing the work wrong. This all contributes to their negative narrative "self-talk" (NF) and an ever-reducing possibility that they can tune into their somatic experience (EF).

The emergent theories outlined above transformed my perspective on the neurodiverse experience and led me to adopt a Social Model of (Dis)ability ${ }^{3}$ within my work. This model recognizes that "socially constructed values [...] make dyslexia a 'problem' and it is society's institutions which need to adapt" (Leveroy 2013, 97) I realized that, rather than fixing or solving a problem in my students' ability to engage with the training, I had to change the approach to training to make it accessible and inclusive. This paradigm shift was key to the progress of my research and is the point of illumination that marks the fourth stage 
of Moustakas' heuristic methodology. Brazilian philosopher and critical pedagogue, Paulo Freire, articulates my experience of illumination when he says,

Well-intentioned professionals [...] eventually discover that certain of their educational failures must be ascribed, not to intrinsic inferiority of the "simple men of the people," [in this case, my neurodiverse students] but to the violence of their own act of invasion. Those who make this discovery face a difficult alternative: they feel the need to renounce invasion, but patterns of domination are so entrenched in them that this renunciation would become a threat to their own identities [...] it would mean abandoning all the myths which nourish invasion, and starting to incarnate dialogical action. (Freire 1996, 137)

I realized that the "invasion" of my pedagogy was the cause of the problem. The subsequent "dialogical action", abandonment of pedagogic "myths", and grappling with my own identity as a teacher, was the next stage of the heuristic process. Moustakas calls this stage explication, a period to "fully examine what has awakened in consciousness, in order to understand its various layers of meaning" (Moustakas 1990, 31). This has at times been a lonely journey, which I described as "losing sight of land" (Oram 2018, 58) and Moustakas refers to as "swimming into an 'unknown current"” (Moustakas 1990, 13).

Freire refers to both traditional and progressive pedagogies as a "banking model of education, where the great guru fills up their students, whose rapt attention does not allow for thinking and action [...] and inhibits their creative power" (Freire 1996, 58). I now knew that this "banking model" was problematic for neurodiverse students; however, I was ignorant as to how I might change it. Critical pedagogue, bel hooks [sic], says that when there is "no model" or "example" of "how to teach in a different way [...] it takes fierce commitment, a will to struggle to let our work as teachers reflect progressive pedagogies"4 (hooks 1994, 142143). In committing fully to the heuristic process of explication, I have strived to find a revised approach to training that liberates neurodiverse students from the oppression caused by experiential learning methods; to work towards a training that allows all students to sustain an experiential (EF) mode of self-reference, in an atmosphere where self-esteem and confidence can thrive.

This dialogical process required me to let go of the position of expert within my teaching. Students responded to this saying, "It really feels like we're teaching him as much as he is teaching us [...] It doesn't feel like he's been teaching for ten years and we're just another installment of people coming through" (Focus Group). Occupying a position of ignorance, where I was guided by my students, took me beyond the critical pedagogy of Paulo Freire, whose own work had grown out of approaches to address illiteracy. By starting from the social model's assumption of inclusivity, I had moved towards the philosophy of Jacques Rancière and the story of The Ignorant Schoolmaster (Rancière 1991). Rancière describes an inversion of critical pedagogy (i.e., starting from an assumption of equality):

As a precondition for the transformation of [...] ideological orders of social inequality within, through, and beyond pedagogical relations. This compliments and deepens Paulo Freire's maxim that 'education is revolutionary futurity [...] This would demand that knowledge production and learning be rooted in a notion of equality in common: the creative collaboration of teachers and students outside the spectre of mastery [emphasis added]. (Means 2011, 43) 
Collaboration and a rejection of mastery are central to the story Joseph Jacotot told in Rancière's book, The Ignorant Schoolmaster. Jacotot was a French university teacher who, in the 1880s, was exiled to the Netherlands. Jacotot spoke no Flemish, and his students spoke no French. Jacotot asked his students to study a bilingual copy of Fenelon's Télémaque. He asked the students to use the Flemish text to begin to read the French. Once they had finished reading the book, he asked them to write about the book in French. Jacotot had limited expectations of the outcome of this exercise but was surprised that they "managed this difficult step as well as many French could have done!" (Rancière 1991, 2). For Jacotot, this was a moment of "revolution" (2), as an "enlightened teacher, he had practiced progressive pedagogic methods, adapting subject matter to students' level [...] At Leuven, however, Jacotot has explained nothing, organized no basic introduction to the French language" (Pelletier 2009, 142). Jacotot concludes "that there is no necessary link between teaching and having knowledge" (142) as it is possible to teach what one does not know. He realizes that emancipation can only be achieved "by establishing a relationship of equality between master and student, between the one who demands that intelligence manifest itself and the other who develops his or her own intellect" (142). It is this process of pedagogic transformation that ties Jacotot's story to my own. Biesta and Bingham, however, make an important point: "Rancière's educational work is not a recipe for any kind of pedagogy. It is a story. It is not a method. It waits not for implementation. It waits instead for another story to be told in return" $(2010,152)$. Rancière's discussion of Jacotot has been useful in the final heuristic stage of creative synthesis, described by McLeod as "finding an appropriate format through which to communicate the new knowledge to other people" $(2011,207)$. The story of Jacotot has helped to disrupt the pedagogic theories that I have inherited and provides a useful counterpoint to the story of my own tacit experiences as a teacher.

Moustakas includes a process of "validation" within creative synthesis but others, such as McLeod, separate it out as a final stage of "eliciting critical and/or affirming responses from others" $(2011,207)$. As the heuristic process often relies on tacit knowing and intuition (Kenny 2012), it is tempting to seek this validation via more "scientific" educational theories. Disability and education academics, Kim Reid and Jan Valle, point out; however, that these developmental educational theories have "exercised a disproportionate influence on special education", and that the "personal, tacit knowledge - that teachers possess must be reinstated over those that owe their lineage to scientistic thinking of one kind or another"cited in (Thomson 2011, 16-21). Reid and Valle believe that "this reinstatement of the personal knowledge of teachers is vital for the development of inclusive education" (21). The psychological theories of education that they reject are also allied to the progressive model of education that I am trying to move away from; therefore, I too have resisted any desire to use them to validate my findings.

My research has produced new knowledge in the study of specific learning differences (SpLDs) and actor training. There is limited existing research in this area and, whilst I found it helpful to refer to in the early stages of my research, ${ }^{6}$ it has not been sufficient for a comparative validation of my findings. To validate my work beyond the boundaries of my initial case study I have shared my research findings with over 300 practitioners and academics internationally through conference presentations, seminars and workshops. This has led to a depth and breadth of dialogue and feedback that both supports my research findings and demonstrates a vital need for this work within actor and voice training. I tell this story here from the perspective of voice training; however, colleagues have already responded that it resonates strongly with their own experiences in teaching acting, 
movement and dance. I do not propose a one size fits all solution, nor do I wish to essentialize the neurodiverse experience. In keeping with the spirit of Jacotot and the principles of heuristic research, I simply tell my story and look to others to tell their stories in return.

\section{Clearing the Fog: Locating the Knowledge}

Somatic practices, such as those developed by Moshe Feldenkrais, F.M. Alexander, Kristin Linklater and Michael Chekhov, ask the acting student to focus on their psychophysical experiences. The goal is to deepen the student's somatic understanding of their body, thought, feeling and voice as they move towards their ultimate acting goal. Linklater refers to this selfknowledge as "awareness," describing it as "the state of being alive, alert and aware that the actor seeks as a launching pad to creativity" $(2006,66)$. The difficulties arise when this primary exploration of self is coupled with a second exploratory process to learn the technique. Not only are the students discovering themselves, but they are also required to discover the exercise or method for themselves through an experiential process guided by the teacher. Linklater acknowledges the challenge of this when she warns students that "progress is slow [...] most of all you must have patience. Even after you understand and practice the exercises, it may take time before you can experience the promised freedom in performance" (Linklater 2006, 11). The consistent evidence from neurodiverse students is that working from this place of confusion leads them into a narrative (NF) mode of self-reference and denies them access to their experiential (EF) learning,

You have to be quite self-aware, which is difficult if you don't know what you are supposed to be aware of [...] its quite difficult in the early stages, you don't know how to lead yourself or what to work on [...] I feel like the work works much better for me if I understand where I'm trying to get to [...] It's important for me to understand why I'm doing what I'm doing. (Focus Group)

I get a sense that, when they're [the teachers] looking at me, that I'm doing something wrong and they're not going to tell me [...] I know you want me to find it for myself but I can't help feeling that, at this stage, it might be better if you told it me now. (Focus Group)

Narrative inner-monologues such as these restrict access to somatic experience and feed into the cycle of failure outlined above. I have experienced a simple, yet radical, paradigm shift within my approach to this work. I no longer see the voice exercises as knowledge to be learnt. The students' growing self-knowledge is now the focus of the fundamental voice training. The voice exercises themselves are the means, by which, that knowledge can be accessed. For the somatic learning to take place, the exercises need to be delivered in the clearest possible way. If the exercises are in any way unclear there is a higher chance that students, especially those who are neurodiverse, will be distracted into a narrative (NF) mode. Just as Jacotot taught his students how to access the knowledge of French contained in the Télémaque, my role is to teach the students how to unlock the hidden knowledge of their own bodies. Jacotot was ignorant of his students' Flemish as I, too, am ignorant of my students' individual somatic experiences. 
It might seem from the student feedback quoted above that the solution is to re-instate some direct instruction into the process, to explain why the exercise is being done and make sure everybody understands how it works. Rockford Sansom advocates a mix of direct instruction and experiential learning in his (2017) article; however, when I tried this approach, I noted that, "in an effort to try and keep everybody on board, it feels like the teaching is grinding to a halt" (Journal Notes). By explaining the work in detail, I was simply giving my already confused students more narrative information to hold onto as they tried to focus on doing the exercises. Explication like this reinforces the expert-novice power dynamic by highlighting the teacher's knowledge, making the student feel even less capable as they try to translate the added narrative information into an embodied experience.

Jacotot describes the explicatory model of education as "stultifying": "There is stultification whenever one intelligence is subordinated to another" (Rancière 1991, 13). To avoid the stultification of direct instruction, progressive educators often use a Socratic method to help students "discover" the knowledge for themselves. Using a series of questions, the teacher leads the student towards pre-determined knowledge in the hope that the student might understand it more deeply, having worked it out for themselves. Rancière describes "the Socratic method of interrogation that pretends to lead the student to his own knowledge" as "the most formidable form of stultification" (Rancière 1991, 59).

For the neurodiverse student, the anxiety of having to discover the right answer, along with constant comparisons of themselves with those who seem to be understanding the work better, and the desire to please teacher with the correct response, can make the stultification of the Socratic method even more acute. When a student does successfully discover the knowledge for themselves, there remains the same problem as with direct instruction and explication; the disconnection between the narrative information and the ensuing experiential application. In the Socratic process, the power of the teacher is reinforced even more than in direct instruction, as the student feels that "alone and abandoned to himself, he would not have followed that route" (59) to understanding.

By rejecting a banking model of education and focusing knowledge production in the body of the student, I am presenting a radical challenge to the established democracy of actor training, which might, in the words of Rancière,

provoke fear, and so hatred, among those who are used to exercising the magisterium of thought. But among those who know how to share with anybody and everybody the equal power of intelligence, it can conversely inspire courage, and hence joy. $(2006,97)$

At its best, actor training should inspire courage and joy and I have seen a transformation in the experience of my students following the changes that I outline below. I will explore some of the specifics of this revised approach through a discussion of a core aspect of the Linklater training, the "sigh of relief" (Linklater 2006, 50-1). The aim here is not to single out Linklater's method for critique. I choose to focus on this work as I have a tacit understanding of it as a teacher and as a student. The work of Freeing the Natural Voice has been deeply effective in my personal vocal development and in that of my students. I use it as an example to highlight how inclusive approaches can be incorporated into a method that has traditionally used experiential learning. In turn, these more inclusive methods might be adopted by other experiential methods of voice, movement and actor training. 
The sigh of relief ${ }^{7}$ sits at the heart of the Freeing the Natural Voice method. Once taught, this fundamental exercise is a key component of all the subsequent voice exercises and is an immensely valuable tool for connecting voice work to acting. Linklater states,

for the actor who wants a voice that will reveal thoughts and feelings rather than merely describing them, exercising the sigh of relief means exercising the connection between thinking and feeling, breath and voice. $(2006,51)$

The voice exercises leading up to and including the sigh of relief follow a recognizable experiential learning process. Students are guided through a process of physical awareness and release, often with their eyes closed. This leads to a guided awareness of breathing and students are asked to "picture the diaphragm moving" (49). At this point, the sigh of relief is introduced. The concepts of breath and impulse underpinning the sigh of relief are discussed through a Socratic dialogue and, later in the process, imagery, such as a parachute or ship's sail, are introduced to deepen the students' experience of the breath in the body. Students are asked to feedback to the group anything that is "fresh", "new" or "interesting" (63) in their experience of the exercises.

The changes that I have made to the introduction of these exercises begin prior to any work on the body, breath and voice and use metacognitive approaches to engage and sustain the students' positive will to learn.

\section{Are We There Yet? Metacognition and the Consciously Unskilled}

You think the teachers are going to think you're disengaged or don't care.

We do care, we think about it all the time! (Focus Group)

This comment from a neurodiverse student was pivotal in my research. It was an essential reminder of the hard work that acting students with learning differences must commit to. It was a reminder that all students have fought against the odds to gain a place at a conservatoire and, despite any contradictory signs, they do indeed "care" and "think about it all of the time." Rancière quotes Jacotot's statement that "Man is a will served by an intelligence" (Rancière 1991, 55). Jacotot calls "the act that makes an intelligence proceed under the absolute constraint of a will, attention" (25). He describes the dual tasks of the teacher as engaging a student's will to learn, and verifying that the intelligence is engaged with attention. During my research, I began to approach my teaching with an unquestioning belief that all students have a strong will to learn. This meant that my dual tasks became, supporting students innate will to learn by helping students avoid entering a cycle of failure, and ensuring that they could pay attention to their bodies' intelligence by maintaining an experiential mode of self-reference (EF).

Mcloughlin et al. authors of The Adult Dyslexic, note that, "understanding one's own thinking processes increases confidence, especially in dyslexic people, who often see themselves as bad at learning-which is not true, it is just that they learn differently" (2002, 108). I have found that helping students to understand the experiential and narrative modes of self-reference has been useful. I explore this metacognitive understanding with my students through practice and they are encouraged to acknowledge what helps them to learn best and how they might avoid being drawn into a narrative mode during the psychophysical exercises - this might be something as simple as realizing that working eyes closed causes them to lose track and switch into a narrative mode to try to work out what the teacher is 
asking them to do. In this way, students become better at reflecting on their work and, rather than reporting that they "got stuck in their head," they now talk about switching to a narrative mode during an exercise and are often able to say what it was that triggered this to happen. This additional level of awareness helps students to review their approach and begin to find strategies to work with increased awareness.

As part of this work on metacognition, I introduce the model of the four stages of learning ${ }^{8}$. This model identifies that before learning any new skill a student will be "unconscious unskilled" i.e. they don't know that they cannot do something. The first stage of learning necessarily involves the student becoming conscious of the fact that they can't do something. The move into this "consciously unskilled" stage can easily spark feelings of failure, especially for those with learning differences. There is no way of avoiding this stage of learning a new skill, but I have found that acknowledging the frustration and attempting to re-frame this moment as one of "possibility", or even celebration, can be helpful in avoiding entering a cycle of failure. In her article, A Pedagogy of Utopia, applied theatre academic, Selina Busby, discusses Ernst Bloch's concept of a "concrete utopia". A concrete utopia occurs where, "through the power of anticipation it is possible to see an 'ideologically unobstructed view" that "leads to a clear understanding of what is now, and maybe what could be in the future" (Busby 2015, 414). When my students have been able to reframe their perceived "failure" as "not yet skilled", their innate will to learn, what Busby refers to as "the power of anticipation", turns the "not yet" into "what might be" (414). This strategy helps students to begin to set clear goals for their own work. bell hooks describes the critical pedagogue's task as empowering "students so that they have the skills to assess their academic growth properly" (1994, 157). By using the concept of "not yet" as a personal goal setting exercise and then using the principle-based learning approaches outlined below, students are more able get feedback and measure their progress, without relying on the expertise of the teacher.

\section{Setting a Course: Principle Based Learning}

Neurodiverse students in my research have clearly indicated a desire for an approach that is measurable in some way. One student explains, "I want to be able to evaluate myself there and then" and "think about things for myself and evaluate it for myself in the moment" (Focus Group). When I introduce the sigh of relief, I break it down into three core principles. Each principle is introduced as a way of examining breathing that will yield new knowledge and awareness. My aim is to give my students the best chance of exploring one thing at a time.

First, though, I demonstrate the exercise. I don't explicate a theory of the sigh, either anatomically or philosophically; I simply demonstrate the process. As Jacotot taught his students to study the Télémaque, so, I teach my students how to study themselves. I lie on the floor and begin to explore the principles of the sigh of relief for myself. I ask my students to observe my breathing and then, in turn, to place their hands on my abdomen to feel the physical action. The principles that I explore for this exercise are;

"Letting Go"- as the breath is released from the body it is neither pushed out nor held back, it is simply released.

"Listening"- between breaths there is a moment of rest in which the actor is available to, or actively listening for, a new impulse of relief. Importantly, 
this listening has a physical location. The first location is in the solar plexus just below the diaphragm.

"Receiving" - an impulse of relief is received into the "listening" solar plexus along with an accompanying breath.

There is little new in these concepts themselves and each of these principles would normally come up in a more traditional explication of the sigh or through a Socratic unpacking of the exercise. My approach; however, is to engage students with each principle practically, in a way that is both transparent and, in some way, measurable. In this way, students can identify what each principle should look or feel like, even if they are not yet able to achieve it.

After my initial demonstration of the exercise, I work with a student in front of the group. I help them to explore each of the principles in turn. If we start with the principle of letting go, we focus solely on that and disregard the principles of receiving and listening. We engage in a collaborative process to explore this single principle. The language and practice of this moment are sophisticated, and I am still working towards a place that feels fully collaborative. Sitting beside the student and working hands-on incorporates an element of somatic dialogue that nurtures rather than instructs. I place most of my attention on this physical connection and find that, if I can remain in an experiencing (EF) mode myself, I am less likely to interpret or explain the student's experience back to them. Anything I do say is related to the somatic experience shared between us, so is less likely to take the student into a narrative (NF) mode. ${ }^{9}$ Applied theatre academic, James Thomas, draws on Eve's Sedgewick's concept of "being 'beside the work' [...] neither above, beyond or looking over, but next to and with" $(2011,134)$. Thomas relates this to Rancière's 'horizontal distributions', which lead to "an examination of 'systems of possibilities' rather than assertions of certainties" (134). Working beside my student and exploring possibilities of change rather than certainties of knowledge, I am going some way towards meeting the demand for more personal learning that neurodiverse students have expressed in focus group sessions ${ }^{10}$ as well as a desire for collaboration in the teaching. "I don't understand why it has to be a student-teacher relationship, why can't it be a more experienced artist and a less experienced artist relationship?" (Focus Group)

After this demonstration, the group get into pairs and take each other through the process. This is an essential component of my revised approach, which means that, for most students, their first encounter with the exercise will be with a peer, who is working from an equal perspective of exploration rather than expertise. "The student must see everything for himself, compare and compare, and always respond to a three-part question: what do you see? what do you think about it? what do you make of it?" (Rancière 1991, 23). The principles give the student something to focus their attention on, to compare and contrast their experience with what they already know of themselves and, whilst they will only rarely work with the teacher, students say that the teaching feels personal.

When discussing success for dyslexic learners McLoughlin et al. state that "the overriding factor is the element to which they have been able to take control of their lives or feel in charge" $(2002,27)$. Peer-learning encourages the students to be in control. Cultural theorist Paul Bowman suggests that Jacotot was "merely encouraging, inspiring or insisting that study take place, without policing the method or result" $(2016,555)$. This is an important aspect in my approach and I now go to great efforts to resist intervention in these peer-led 
explorations. As soon as I intervene in this initial exploratory work, I reinforce my dominance as the expert. This then leads the student to stop asking, "what am I discovering?" and to begin to question, "am I doing it right?" Stepping away from "policing" helps to remove a dependency on the teacher that the progressive and Socratic approaches can often create, as student comments show:

I've not got strategies to sustain the work because it's quite in the moment and it would be useful if there were things [to sustain it] [...] I'm finding it hard to practice [...] [the teacher] actually helps but I can't have them by my side every day. (Focus Group)

The peer-learning pairs discuss their findings together and then share feedback with the whole group. I do not "police" this feedback in any way, there is no prescription of what language to use, no steering away from negative thoughts or frustrations, and no interpretation or explication. I simply accept the retelling of what happened and prompt the students to make sense of it in their own way. Building genuine trust in my students' experiences and sustaining the belief that they will learn what they need within the context of the training is fundamental to this approach. Biesta and Bingham quote Rancière's perspective on trust,

the one who doesn't start from here but instead starts out from distrust, and "who assumes inequality and proposes to reduce it" can only succeed in setting up "a hierarchy of inequalities $[\ldots]$ and will produce inequality ad infinitum." $(2010,41)$

Trust building helps to overcome neurodiverse students' misguided belief in their own inabilities, reduces any anxiety they have as to what the teacher will think of them, and nurtures their innate will to learn.

There are additional advantages for neurodiverse students in discussing the work in pairs before speaking. Dyslexia and dyspraxia tutors, Tanya Zybutz and Colin Farquharson have identified the difficulty that dyspraxic students have in translating a narrative instruction into a physical experience (Zybutz and Farquharson 2016). Dyspraxic students will, similarly, find it difficult to translate back from the experiential mode of doing an exercise into the narrative mode of giving feedback. A further strategy that helps with this translation, is to ask students to remain on the floor in the physical orientation and experiential state of the exercise and to ask them to try and find a word, phrase or image to communicate what is going on for them in the moment of experience. By working with feedback in this way, I am hoping to strengthen my students' ability to come into language, whilst staying connected to their sensory selves, a key tool for the actor. ${ }^{11}$

Whilst the dyspraxic student might struggle to translate their experiences into narrative feedback, the dyslexic student may struggle to organize their thoughts into a coherent form. Authors of The Dyslexic Advantage, Brock and Fernette Eide, explain that "although Albert Einstein [who was dyslexic] eventually became a talented writer, he once complained that thinking in words was not natural for him [...] To communicate verbally he needed first to 'translate' his almost entirely nonverbal thoughts into words" (2011, 64-5). One of my students described their experience of full-group feedback saying, "you hear someone else and they say it much better and, you're like, I couldn't phrase it like that, I'd get lost. They're much more to the point and I can't seem to put things together in my mouth" 
(Focus Group). Again, peer-to-peer feedback is an ideal way for dyslexic students to collect their thoughts and rehearse what they want to say.

Teachers of Freeing the Natural Voice are trained to request student feedback in specific ways. For example, students are asked to speak in the first person singular-"I felt", rather than "you feel". The suggestion here is that, by saying "I," the student connects more effectively to their felt experience. For neurodiverse students who struggle to formulate feedback, this is an added level of complexity. The fear of getting it wrong can be enough to stop them from sharing their thoughts at all. Students are also asked to fit their experiences into a prescribed framework, to feedback first, only what was "fresh", "new" or "interesting". This process is to intended to "tackle a persistent tendency many of us have to be selfdenigrating, self-judging, and ultimately more ready to fail than to succeed" (Linklater 2006, 62). The danger is that it can require the student to disengage from their primary experience in order to construct the requested narrative response.

I find [fresh, new and interesting] difficult. I feel like there's a barrier now because I'm not feeling anything positive [...] right now it feels negative and the only way I'm going to find out what's positive is if I work through it because the truth is, there is a negative. (Focus Group)

Teachers also guide students to use specific language such as "when I let the breath go" rather than "when I breathed out". This approach implies that language has an essential quality that unlocks a universal experience of breath in each person. Rancière confronts the idea of universal truths when he states that "each one of us describes our parabola around the truth. No two orbits are alike." (Rancière 1991, 59) Rancière describes language as arbitrary and the process of one person trying to communicate their personal truth to another through arbitrary language as poetic.

The democratic man is a being who speaks, which is to say a poetic being, a being capable of embracing a distance between words and things which is not deception, not trickery, but humanity; a being capable of embracing the unreality of representation. A poetic virtue, then, and a virtue grounded in trust. (Rancière 2007, 51)

Again, trust takes the place of control in the student-teacher relationship and the performative and artistic benefits of trying to find a personal language to convey individually felt experiences is recognized. Teaching from the perspective of tangible and measurable principles allows students to relate to something specific. Accepting any language of feedback recognizes that the experience associated with those principles will be in no way universal.

This principle-based approach does make the foundational teaching slower and, initially, I was fearful that I would not get through the amount of work that I intended. bell hooks cautions teachers that "to focus on covering material precisely is one way to slip back into the banking system" $(1994,156)$ and I, again, had to learn to trust the collaborative process taking place between myself and the students. Student feedback shows the value of this: 
I always walk away feeling I've learnt something [...] I've enjoyed the way he has started with principles from the first lesson, taking the time we needed to move slow. (Focus Group)

As it transpires, the changes made have enabled students to take the exercises on more effectively and have given them the ability revisit them by themselves or with peers. The basic principles of the foundation work are now learnt deeply by all students, regardless of any neurodiversity. I find that I can move through more advanced explorations without needing to go back and review the basics.

The principles described above act as anchors, which help the neurodiverse student stay in an experiential mode. In the following section, I describe further anchors used to sustain this process of working with attention.

\section{Dropping Anchor: Staying with the Experience}

The hands-on explorations described above are an example of the use of physical anchors that are particularly helpful in giving dyspraxic students a better awareness of their bodies ${ }^{12}$. The Freeing the Natural Voice work often uses hands-on approaches and many of the existing exercises helpfully allow students to use their own hands on their body to focus their attention when working by themselves. I have found it useful to revisit the core principles and hands-on work whenever the physical orientation of the exercise changes for the first time. For example, if the initial exploration of the sigh of relief has been done lying on the floor, I will guide students to revisit the principles when we move to standing. This is helpful as, in standing, the diaphragm is now moving in a different direction in relation to gravity, and the physical sensation of letting go will change. If I am taking students through a new sequence of movements, e.g. from semi-supine, to prone, to child's pose/folded leaf, to hanging over and then rolling up through the spine to standing, I will explore the physical journey first. I will take the students from one position to another to understand the choreography of the body without the distraction of breath or voice exercises, then, I will spend time to review the principles in each position. Only then, would I lead the class through a flowing progression from beginning to end; the benefit being that all students are orientated to the sequence, able to experience it somatically, and can feedback on what they learned about themselves.

I described in my previous article (Oram 2018) how neurodiverse students can get lost when working eyes-closed - this could be due to disorientation or a lack of visual clues to help translate narrative instructions into physical experience. Students now choose whether to work with their eyes closed or open. This enables students keep attention on their experience without the narrative distraction of trying to keep up with the class.

Keeping a journal or other form of record is another process that anchors learning. However, in many psychophysical approaches note taking is discouraged. Polish theatre director, Jerzy Grotowski's psychophysical training uses pedagogical approaches familiar to this discussion. He says,

If during our meeting you take notes or record on tape, you preserve from this meeting only some formulas. If you search for formulas, you search for revered truths. Just listen and somehow participate in this event. You can forget all the formulas. By themselves, they mean nothing - cited in (Salata 2013, 38) 
Here, Grotowski reinforces Rancière's rejection of revered truths and guides the participant towards their experience (EF). Iris Warren, upon whose work Freeing the Natural Voice is based, instructed Kristin Linklater that the work "should never be written down" (Linklater 2006, 10). I am sure that relates in some way to the preference for individual experience over empirical truths. Note taking can be additionally problematic as it takes the student into a narrative mode and away from experiencing. However, if a student has made a valuable discovery and is trying to remember it so that they can write it down after the class, they will be forced to stay in a narrative mode, which will disengage them from further somatic experiences. Students in my classes now take notes as best suits them and we discuss this in relation to the problems outlined above. Notetaking does not work for all students and many will prefer to record sessions. I have also begun to resource the students by making short films. I film myself as I work through the core principles in class and I put these on the internet. The students can then revisit the work exactly as they first experienced it.

If I am teaching students the components of a warm-up over a teaching term/semester, I send them a preliminary film of the eventual warm up before the first class. This helps to provide a temporal anchor and orientates the students to the bigger picture; giving them a gist of what is to come. This is of use to dyslexic students who have, what Eide and Eide call, "big-picture" $(2011,91)$ strengths. Linklater's book, Freeing the Natural Voice (2006), is also a helpful reference. Sometimes teachers restrict students from reading ahead beyond the work covered in class. Again, this comes from a progressive learning model where there is a fear of end-gaining and a desire for the students to discover the work experientially. Eide and Eide suggest that for dyslexic students,

Previewing practical relevance and applicability of the information they'll be asked to master will improve retention [...] and beginning each new course or unit by previewing the major points that will be asserted, and the route that will be taken to demonstrate them, can keep dyslexic students better orientated, more confident, and better able to learn. (100)

I encourage students to access written resources as and when it suits them. I also give an overview to each class, term/semester, and the entire arc of the training, to anchor and orientate students within the process. The anchors discussed here help the actor stay connected to the tangible experience of the exercises; however, a further aspect of an actor's training is the development of the imagination. Psychophysical training draws on imagery to help develop the actor's ability to inhabit worlds beyond the tangible here and now of the acting studio and this work requires a special mention in relation to neurodiversity.

\section{Dreaming of the Stars: Imagery and Imagination}

Linklater states that "Imagination in the head is not of much use to the actor [...] but embodied imagination is the stuff of acting" $(2006,66)$. This is a useful reminder that the approach to working with imagery needs to be one that allows students to stay in an experiential mode and not get distracted into a narrative mode. Much of the literature on dyslexia attributes a visual learning style to dyslexic students (McLoughlin, Leather and Stringer 2002; Davis 1997, 2003; Grant 2010); however, my research has found that dyslexic and/or dyspraxic students can find image-based teaching problematic. Eide and Eide provide evidence to support my findings when they discuss research into problem solving and imagery. The research shows that when the problems "contained terms that provoked strong 
visual imagery unrelated to the reasoning process [...] the dyslexic students performed significantly worse than the nondyslexics" $(2011,66)$. They go on to say:

The potentially distracting role of visual imagery has important implications for how we teach dyslexic students with strong imagery abilities [...] Many teachers have been taught that using imagery helps children with strong spatial and visual skills, but this is true only if the imagery is directly useful for solving the problem. (66)

This understanding has been helpful in reviewing the process by which I introduce imagery into my teaching.

The approach outlined in this article prioritizes the deepening of students' somatic experiences and their ability to work with awareness. I have rejected any belief that the language or imagery associated with an exercise contains essential knowledge itself. Instead, I approach the work through collaboration, negotiation and translation, and focus students' attention on their emergent self-knowledge. I have begun to see imagery as being much broader than simply things that we can "see" or "picture" in our minds. Linklater supports this saying "imagery is not confined to the visual. All the other senses contribute 'imagery' to the body-mind" $(2006,66)$. She goes on to quote from Antonio Damasio's The Feeling of What Happens,

Images are constructed either when we engage objects, from persons and places to toothaches, from the outside of the brain towards its inside; or when we reconstruct objects from memory, from inside out, as it were [...] One might argue that images are the currency of the mind (67)

When I considered my teaching from this expanded perspective of imagery, I realized that neurodiverse students who were already sensitive to imagery were being overloaded. When students observe my demonstration of the sigh of relief, they receive the visual image of my body and breath, along with the tactile image of the feeling of breath and movements of my torso. That amounts to two sets of imagery. When I add a single principle such as letting go, this is a third image for them to take on board. This is already a lot to hold in the body-mind and reinforces my decision to move from one principle to another, one step at a time.

Once the students have embodied the core principles, I begin to introduce them to some of the anatomical structures. I agree with Rockford Sansom (2017) that the inclusion of empirical scientific knowledge in actor training can be helpful for some students. Using anatomical models or pictures does; however, involve a complex process of translation. No matter how detailed the anatomical picture of the diaphragm is, it is still an image that needs translating into the body. Student feedback showed that it was unhelpful to introduce anatomical imagery before an exercise was explored physically as there was simply too much to deal with. After an exercise has been embodied; however, students find that spending time to really connect anatomical imagery into their individual experience is "very useful [...] it enabled me to get to grips with all the different dimensions and how it compares to how I'm feeling [...] I was able to get my bearings [...] then images are more vivid" (Focus Group).

Similarly, a careful introduction of more creative imagery can be very useful. Working with the image of a parachute or ship's sail connected to the movement of the 
diaphragm in the sigh of relief can deepen the experience for some students. The problem comes when creative imagery is used to introduce a new exercise. In which case, there is an overload of instructions [images] and the creative imagery is experienced as "unrelated to the reasoning process" (Eide and Eide 2011, 66). Again, creative imagery, like anatomical imagery, becomes effective after the core principles of a new exercise have been embodied. When I do offer imagery to deepen an exercise, students are aware that they can reject it or come up with their own if they prefer. Additionally, for those students who are more kinesthetic learners, learning to translate is important. For these students, the image of the parachute is better felt as a silky soft fluttering in the abdomen rather than pictured as a brightly colored dome underneath the ribs. We spend time in class practicing the translation of visual images into kinesthetic experiences and students are encouraged to translate for themselves at any point.

Imagery has the benefit of moving the work into a state of flow, away from the detail towards the big picture. It is essential for actors to continually move the voice work into an imaginative relational context. The attention to detail that $I$ have set out in the work here is only of value when it is able to be abandoned by the student as they come into work for performance. Linklater stresses this very point, "it is at best inefficient, and at worst destructive, to separate the training of voice and body from the imaginative process" (Linklater 2016, 60). When the work begins to move into an imaginative world, the teacher's role changes to that of coach. I find it helpful to support my students at this point by saying "you can focus on the imaginative world and the relationships, I'm here to keep an eye on the principles." And, because the principles are understood and shared between myself and the students, they are a valuable reference point in supporting their performance work. Once again, the student is responsible for understanding and making sense of their experience and, in the spirit of Jacotot, I am there to verify that the work is done with attention.

\section{Returning to Land: Conclusion}

I have shown how the progressive educational model at the heart of psychophysical actor training dysconsciously discriminates against students who are dyslexic and/or dyspraxic learners. I have enabled all students, regardless of neurodiversity, to have better access to the training by rejecting the pedagogic myths at the heart of the progressive model and adopting the approaches of critical pedagogy. The social model of (dis)ability assumes equality at the outset and has resonances with the utopic vision of equality at the heart of the story of Joseph Jacotot and the radical philosophy of Jacques Rancière. I do not propose to have created an emancipatory school of acting by incorporating Jacotot's story into my work. Indeed, the final chapters of The Ignorant Schoolmaster show how any attempt to establish a formal school based on Jacotot's methods is doomed to failure. However, by adopting a philosophical approach that starts from an assumption of equality and then testing that at every stage, I have found a less stultifying approach to training. The success of this work relies on trust, collaboration and a rejection of the traditional expert-novice power dynamic within actor training. My research started from a position of ignorance in relation to my students' learning. The outcome of this research allows me to maintain that position as a coinvestigator beside my students as they learn deeply about themselves in relation to their performance goals.

For my future teaching and research, I am keen to continue a process as co-investigator with my students. The dialogical process of focus groups has been crucial to understanding the student experience and I am keen to retain this type of discussion in my ongoing pedagogy. I 
believe that there is potential within the heuristic approach and critical pedagogy to investigate further aspects of inclusion within voice training and have already begun to explore this in relation to diversity, inclusion and speech and accents training. Within the area of learning differences and actor training, I encourage colleagues to investigate the impact of the findings outlined here within their own teaching practice and to begin to tell their own stories and add to the growing knowledge in this under-researched area.

For my students, I hope that the metacognitive skills outlined here help to prepare them for a professional life where power dynamics and stultifying processes still dominate. As more neurodiverse actors are enabled to succeed in training and enter the profession, there is also the potential for change within the industry. If actors who experience themselves as different, in any way, are celebrated and supported through their training without resistance, then there is the potential for what Rancière would call dissensus, as they go on to present a political challenge to the status assigned to them by the hegemony of the performing arts industry.

\section{References}

Biesta, Gert, and Charles Bingham. 2010. Jacques Rancière Education, Truth, Emancipation. London: Continuum International Publishing Group.

Bowman, Paul. 2016. "The Intimate Schoolmaster and the Ignorant Sifu: Postructuralism, Bruce Lee, and the Ignorance of Everyday Radical Pedagogy." Philosophy and Rhetoric 49 (4): 549-570.

Busby, Selina. 2015. "A Pedagogy of Utopia." Research in Drama Education: The Journal of Applied Theatre in Performance, 20 (3): 413-416.

doi:10.1080/13569783.2015.1059259.

Davis, Ronald. 1997. The Gift of Dyslexia. London: Souvenir Press.

—. 2003. The Gift of Learning. New York: Penguin Group.

Eide, Brock, and Fernette Eide. 2011. The Dyslexic Advantage: Unlocking the Hidden Potential of the Dyslexic Brain. London: Hay House UK Ltd.

Farb, Norman, Zindel Segal, Helen Mayberg, Deborah Mckeon, Zainab Fatima, and Adam Anderson. 2007. "Attending to the Present: Mindfulness Mediation Reveals Distinct Neural Modes of Self-Reference." Social Cognitive and Affective Neuroscience. 2 (4,1): 313-322. doi:10.1093/scan/nsm030.

Freire, Paulo. 1996. Pedagogy of the Opressed. London: Penguin.

Grant, David. 2010. That's the Way I Think: Dyslexia, dyspraxia and ADHD explained. New York: Routledge.

hooks, bell. 1994. Teaching to Transgress: Education as the Practice of Freedom. Abingdon: Routledge. Taylor and Francis Group.

Kenny, Gerard. 2012. "An Introduction to Moustakas's Heuristic Method." Nurse Researcher 19 (3): 6-11. doi:10.7748/nr2012.04.19.3.6.c9052. 
Leveroy, Deborah. 2013. "Enabling Performance: Dyslexia, (Dis)ability and 'Reasonable Adjustment'." Theatre Dance and Performance Training 4 (1): 87-101. doi:10.1080/19443927.2015.1065464.

Linklater, Kristin. 2006. Freeing the Natural Voice; Imagery and Art in the Practice of Voice and Language. London: Nick Hern Books.

—. 2016. "The Art and Craft of Voice (and Speech) Training." Journal of Interdisciplinary Voice Studies (Intellect Ltd) 1 (1): 57-70. doi:10.1386/jivs.1.1.57_1.

McLeod, J. 2011. Qualitative Research in Counselling and Psychotherapy. London: Sage Publiations.

McLoughlin, D, C Leather, and P Stringer. 2002. The Adult Dyslexia. London: Whurr Publishers.

Means, Alexander. 2011. "Jacques Rancière, Education, and the Art of Citizenship." Review of Education Pedagogy and Cultural Studies. 33 (1): 28-47. doi:10.1080/10714413.2011.550187.

Moustakas, Clark. 1990. Heuristic Research: Design, Methodology, and Applications. Newbury Park CA: Sage.

Oram, Daron. Forthcoming. "Chekhov Technique and Voice." In Michael Chekhov Technique in the Twenty First Century: New Pathways. Bloomsbury Methuen Drama.

Oram, Daron. 2018. "Losing Sight of Land: Tales of Dyslexia and Dyspraxia in Psychophysical Actor Training." Theatre Dance and Performance Training. 9 (1): 5367. doi:10.1080/19443927.2017.1415955.

Oram, Daron. 2015. "Research and Practice in Voice Studies: Searching for a Methodology." The Voice and Speech Review. 9 (1): 15-27. doi: 10.1080/23268263.2015.1059674.

Pelletier, Caroline. 2009. "Emancipation Equality and Education: Rancière's Crititque of Bourdieu and the Question of Performativity." Discource: Studies in the Cultural Politics of Education.137-150. doi:10.1080/01596300902809054.

Rancière, Jacques. 2006. Hatred of Democracy. London: Verso.

Rancière, Jacques. 2010. "On Ignorant Schoolmasters." In Jacques Rancière Education, Truth, Emancipation, by Charles Bingham and Gert Biesta, 1-24. London: Continuum International Publishing Group.

—. 2007. On the Shores of Politics. London: Verso.

—. 1991. The Ignorant Schoolmaster: Five Lessons in Intellectual Emancipation. Translated by K. Ross. Stanford, California: Stanford University Press.

Salata, K. 2013. The Unwritten Grotowski : Theory and Practice of the Encounter. London: Routledge. (Routledge advances in theatre and performance studies).

Sansom, Rockford. 2017. "The Unspoken Voice and Speech Debate [or] the Sacred Cow in the Conservatory." Voice and Speech Review. 10 (2-3): 157-168. doi:10.1080/23268263.2016.1318814. 
Thomas, Gary. 2009. "An Epistomology for Inclusion." In Psychology for Inclusive

Education: New directions in theory and practice, by Peter Hick, Ruth Kershner and

Peter Farrell, 11-23. Abingdon: Routledge.

Thomson, James. 2011. Performance Affects: Applied Theatre and the End of Effect. London: Palgrae Macmillan.

Zybutz, Tanya, and Colin Farquharson. 2016. "Psychophysical Performance and the Dyspraxic Actor." Journal of Neurodiversity in Higher Education 2: 76-87.

\section{Notes}

${ }^{1}$ Throughout this article I refer to notes from my own reflective journaling and student focus group sessions, which were led by an external facilitator. I do not date these focus group quotes as they reflect opinions from students who might be more easily identified by the dates relating to their training.

${ }^{2}$ There is neurodiversity across the entire population. I use the term neurotypical in the article to refer to those students who do not identify as dyslexic and/or dyspraxic learners.

${ }^{3}$ I discuss this model in depth in my previous article (Oram 2018, 57-8). In this discussion, it might more specifically be referred to as a social model of learning difference rather than (dis)ability.

${ }^{4}$ hooks' reference to "progressive" in this case refers to a move towards critical pedagogy.

${ }^{5}$ The term "special education" has historically been used in the UK education system to include teaching for students with learning differences and disabilities.

${ }^{6}$ For more detail, see (Oram 2018, 56).

${ }^{7}$ The sigh of relief encourages the actor to work from a "causal impulse [...] creating and re-creating a genuinely felt sigh of relief as the underlying energy for breathing and voice" (Linklater 2006, 51) - as opposed to consciously controlled anatomically oriented breathing exercises. The sigh of relief helps the actor to let go of deliberate control of the breathing and give over to thought/feeling as the causal impulse for breath. The actor can then exercise the impulse e.g. a bigger thought/feeling to increase breath capacity.

${ }^{8}$ This model was first outlined by Martin Broadwell in 1969

http://www.wordsfitlyspoken.org/gospel guardian/v20/v20n41p1-3a.html and was then developed by Noel

Burch of Gordon Training International during the 1970s http://www.gordontraining.com/free-workplacearticles/learning-a-new-skill-is-easier-said-than-done/\#. The stages of learning are, Unconscious Incompetence, Conscious Incompetence, Conscious Competence and Unconscious Competence-although, I prefer the later rewording of Unconsciously Unskilled etc.

${ }^{9}$ It is important that with any work involving touch between teachers and students, or between students themselves, that issues of consent and appropriate contact are explored. I have been particularly impressed by Saul Kotzubei's approach to this. Saul is director of the Fitzmaurice Institute and takes his students and teachers through a process of practicing saying "no" before moving on to consent.

${ }^{10}$ Eide and Eide also discuss the personal learning preferences of dyslexic students. $(2011,14)$

${ }^{11}$ I discuss this psychophysical connection between voicework and acting in my book chapter on Michael Chekhov technique and Voice. (Oram forthcoming)

${ }^{12}$ Anecdotally, this hands-on work is also beneficial in helping students with an ADD/ADHD diagnosis, which is commonly comorbid with dyspraxia. 